\title{
ELECTROCHEMICAL PRESSURE GENERATION
}

\author{
T. Stanczyk, B. Ilic, P.J. Hesketh, J. Boyd \\ Microfabrication Application Laboratory \\ Department of Electrical Engineering and Computer Science, University of Illinois at Chicago \\ Chicago, Il 60607
}

\begin{abstract}
Electrochemical pressure generation between two platinum electrodes, and a reference $\mathrm{Ag} / \mathrm{AgCl}$ electrode, has been investigated. The electrodes were immersed in a $\mathrm{H}_{2} \mathrm{SO}_{4} / \mathrm{KCl}$ solution and were subject to varying currents from a galvanostat. The desired reaction was $\mathrm{O}_{2}$ production at the working electrode although several parasitic reactions came into play. These were divided into desired parasitic (production of $\mathrm{H}_{2}$ at the counter electrode and the production of $\mathrm{Cl}_{2}$ at the working electrode) and unwanted parasitic reactions (reduction of $\mathrm{O}_{2}$ to $\mathrm{H}_{2} \mathrm{O}$ at the counter electrode and oxidation of $\mathrm{H}_{2}$ to $\mathrm{H}^{+}$ at the working electrode). The calculated values of the time to pressurize a cavity of $1.35 \mathrm{~cm}^{3}$ (at varying currents and assuming $\mathrm{O}_{2}$ production as the main reaction) to a value of 2000 $\mathrm{Pa}$ were compared to the experimental values. In each case, the experimental value was more then twice as fast as the calculated one. This is mainly due to the desired parasitic reactions that take place. At a current of $250 \mathrm{~mA}$ the time recorded to reach $2000 \mathrm{~Pa}$ was 0.6 seconds. The short amount of time to pressurize a chamber this size and the facts that relatively little power was consumed and that high pressure can be maintained with out extra power input, suggest that this mechanism of pressure generation would be good for precise liquid dispensing schemes.
\end{abstract}

\section{INTRODUCTION}

Electrochemical actuation is a relatively new way of creating large amounts of pressure based on electrolysis of an aqueous electrolyte solution. It has been previously investigated by Janchoa [1] and Kempe [2]. The electrolysis is driven by a potential that is applied to a working and a counter electrode. Depending on the metals used as the electrodes and the potential applied, gas can be generated at one or both of the electrodes. Neagu [3] has previously generated oxygen through the use of copper and platinum electrodes. Three-electrode systems also exist in which a potential is applied with respect to a reference electrode. The benefit of the three-electrode system is having a stable applied potential and knowing what reactions are taking place at that potential. In a closed system, pressure can be generated by gas formation and the reverse reactions can also be accomplished by shorting the electrodes or by switching the polarity. The reverse reactions depend upon the kinds of metals used for the electrodes and any other coating which may be used, such as Nafion [3], to limit negative ions and non-polar compounds from diffusing toward the electrodes. Otherwise, if pressure is generated and the applied voltage is cutoff, (ideally) the pressure would remain constant. Although this depends on a couple of factors: 1) how well the cavity is sealed and 2) any reverse reactions due to the standard reduction potentials.
Depending on these variables, a pressure could be maintained for a long period of time with minimal power input.

\section{THEORY}

When a voltage greater than the equilibrium potential is applied between two electrodes, the production of gas is governed by the Faraday equation $n=(I t) / F$, where $n=$ the number of moles of gas, $I=$ the current flow, $t=$ the time of the applied voltage, and $\mathrm{F}=96487 \mathrm{C} / \mathrm{mol}$ (Faraday's constant). At atmospheric pressure this gas will occupy a volume $\mathrm{V}$ given by $\mathrm{V}=\mathrm{n}(\mathrm{RT}) / \mathrm{P}$, where $\mathrm{R}=8.314 \mathrm{~J} / \mathrm{mol} / \mathrm{K}, \mathrm{T}=$ temperature in Kelvin, and $P=$ pressure. From this one can calculate the time necessary to inflate a rigid chamber to a desired pressure given that this is the desired (half-cell) reaction:

$2 \mathrm{H}_{2} \mathrm{O}=\mathrm{O}_{2}+2 \mathrm{H}^{+}+4 \mathrm{e}$

Although there are other parasitic reactions that happen:

$\begin{array}{lll}\text { Counter electrode } & 2 \mathrm{H}^{+}+2 \mathrm{e}=\mathrm{H}_{2} & 0.000 \mathrm{~V} \\ & \mathrm{O}_{2}+2 \mathrm{H}^{+}+4 \mathrm{e}=2 \mathrm{H}_{2} \mathrm{O} & 1.229 \mathrm{~V} \\ & \mathrm{Pt}+4 \mathrm{Cl}^{-}=\mathrm{PtCl}_{4}{ }^{2-}+2 \mathrm{e} & 0.730 \mathrm{~V} \\ & & \\ \text { Working electrode } & \mathrm{H}_{2}=2 \mathrm{H}^{+}+2 \mathrm{e} & 0.000 \mathrm{~V} \\ & 2 \mathrm{Cl}^{-}=\mathrm{Cl}_{2}+2 \mathrm{e} & 1.358 \mathrm{~V}\end{array}$

At the high potentials used there might be Platinum Chloride formation on the anode, which could impede gas formation. However, using two platinum electrodes has the advantage that the reduction potential between them is not a factor. Also, platinum is inert so that there is no oxide formation that can be a problem when other metals are used.

\section{EXPERIMENTAL DETAILS}

Figure 1 is the experimental layout used for our experiments. The electrochemical experiments were done inside of a teflon chamber that had 4 port connections. One port was used to connect the pressure sensor. The second port was used to insert the $\mathrm{Ag} / \mathrm{AgCl}$ reference electrode. The third port was connected to a nitrogen tank. This was done in order to pressurize the chamber and measure the leakage rate (while no chemicals were present). The fourth port was where the platinum electrodes were inserted in order to seal the teflon cavity. The total volume of the teflon chamber was $1.73 \mathrm{~cm}^{3} .0 .35 \mathrm{~cm}^{3}$ of the cavity was filled with the 9 part $0.1 \mathrm{M} \mathrm{H}_{2} \mathrm{SO}_{4} 1$ part $0.1 \mathrm{M} \mathrm{KCl}$ solution. The $\mathrm{KCl}$ was present so that the $\mathrm{Cl}$ from the $\mathrm{Ag} / \mathrm{AgCl}$ reference electrode would not dissolve into solution. The platinum electrodes that were used were made on [100] P-type silicon wafers. $2500 \mathrm{~A}$ of nitride was deposited and then $2000 \mathrm{~A}$ of platinum was sputtered at $110 \mathrm{~W}$ on the unpolished side of the 
wafer. Subsequent to photolithography, Aqua Regia $(\mathrm{HCl}+$ $\left.\mathrm{HNO}_{3}\right)$ was used to etch the platinum and then Piranha $\left(\mathrm{H}_{2} \mathrm{SO}_{4}{ }^{+}\right.$ $\mathrm{H}_{2} \mathrm{O}_{2}$ ) was used to clean the platinum surface. The approximate size of each electrode that was exposed to the solution mixture was $4.0 \mathrm{~mm}^{3}$ (the electrodes themselves are each $6.1 \mathrm{~mm}^{3}$ ). The

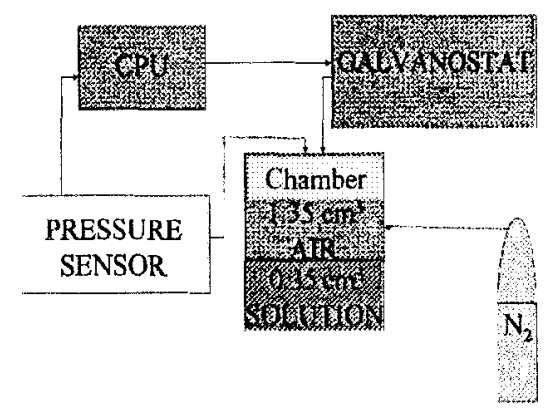

Figure 1. Experimental Setup

$\mathrm{Ag} / \mathrm{AgCl}$ reference electrodes were made in the lab from 0.01 " $\mathrm{Ag}$ wire. The specified potential of $\mathrm{Ag} / \mathrm{AgCl}$ electrodes vs. NHE was $-0.045 \mathrm{~V}$ although we repeatedly obtained a value of $-0.068 \mathrm{~V}$ [4]. O-rings were also placed throughout the chamber in order to minimize leakage. When tested for this, the leakage rate was $1 \mathrm{~Pa} / \mathrm{s}$ at moderate ( 2 to $5 \mathrm{kPa}$ above atmosphere) pressures. The galvanostat was hooked up to the two platinum electrodes and to the $\mathrm{Ag} / \mathrm{AgCl}$ reference electrode. Then different currents of $1 \mathrm{~mA}, 10 \mathrm{~mA}$ and $250 \mathrm{~mA}$ were applied to see the pressure generation rate. At $1 \mathrm{~mA} 2000 \mathrm{~Pa}$ was generated in 250 seconds. At $10 \mathrm{~mA}$ the same pressure was achieved in 19 seconds (Fig. 2). In both cases, the actual rate of gas production was more than twice as fast as the calculated values.

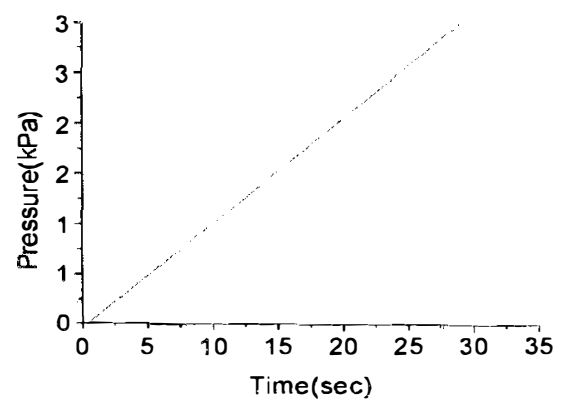

Figure 2. At $10 \mathrm{~mA}, 2000 \mathrm{~Pa}$ was generated in 19 seconds. The calculated value, considering $\mathrm{O}_{2}$ generation only, is 42.7 seconds.

At a current of $250 \mathrm{~mA}$ the pressure rise was rapid and went above a value of $27,000 \mathrm{~Pa}$ in less than 50 seconds. It took only 0.6 seconds to generate a pressure of $2000 \mathrm{~Pa}$ at this rate (Fig 3). The rate in this run was also more then twice as fast as the calculated rate. We reasoned that this was from the generation of hydrogen and chlorine gas. This was confirmed when we took a voltammogram of our setup (Fig 4). The wave, which occurs at approximately 1.25 volts, is an indication of $\mathrm{Cl}_{2}$ evolution.

\section{CONCLUSIONS}

The advantage of an electrochemical pressure generation is that once the pressure is built it should not change. This, however, is ideal and assumes no gas loss whether it is due to leakage through the chamber or due to reverse reactions. By two platinum electrodes in the three-electrode system we tried to minimize the reverse reactions and other retarding reactions. In the process we actually achieved faster pressure generation, $2000 \mathrm{~Pa}$ in 0.6 seconds, due to $\mathrm{Cl}_{2}$ and $\mathrm{H}_{2}$ generation in addition to the $\mathrm{O}_{2}$ generation. However, there are still issues that have to be dealt with: 1) the sealing of the cavity, 2) reducing any oxygen and chloride reduction or hydrogen oxidation, and 3 ) reducing the formation of Platinum Chloride.

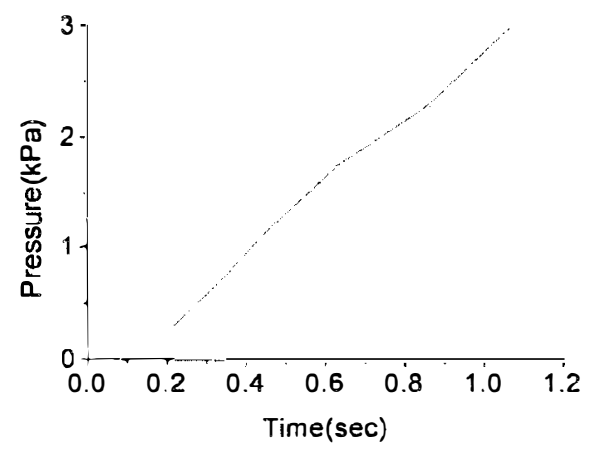

Figure 3. At $250 \mathrm{~mA}$ a pressure of $2000 \mathrm{~Pa}$ was generated in 0.6 seconds

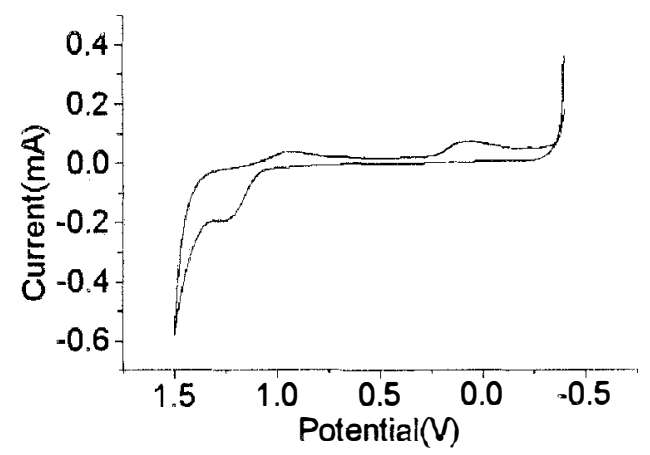

Figure 4. A voltammogram done with between two platinum electrodes in a 9 part $0.1 \mathrm{M} \mathrm{H}_{2} \mathrm{SO}_{4} / 1$ part $0.1 \mathrm{M} \mathrm{KCl}$ solution. $\mathrm{Ag} / \mathrm{AgCl}$ reference electrode was used

\section{ACKNOWLEDGEMENTS}

The authors would like to acknowledge and thank DARPA (grant \# N66001-97-1-8911), for their financial support, and Tony Cocco, for his technical assistance.

\section{REFERENCES}

1. H. Janocha, "Neu aktoren", Proc. Actuator, 88, 389 (1988).

2. W. Kempe and W. Schapper, "Electrochemical actuators", Proc. Actuator, 90, 162 (1990).

3. C.R. Neagu, J.G.E. Gardiers, M. Elwenspoek, and J Kelly, "An electrochemical Microactuator: Principle and First Results", Journal of Microelectromechanical Systems, 5, 1 (1996).

4. A.E.G Cass, Biosensors, Oxford University Press, New York, 1990, pp. 60-61. 